\title{
Multi-Database Description of Primary Splenic Diffuse Large B-Cell Lymphoma
}

\author{
KENNETH P. BYRD ${ }^{1,2}$, NAMRATHA R. VONTELA ${ }^{1,2}$, BRENNAN MCCULLAR $^{1}$ and MIKE G. MARTIN ${ }^{1,2}$ \\ ${ }^{1}$ Department of Hematology/Oncology, University of Tennessee Health Science Center, Memphis, TN, U.S.A.; \\ ${ }^{2}$ The West Cancer Center, Memphis, TN, U.S.A.
}

\begin{abstract}
Background/Aim: Stage I splenic diffuse large $B$-cell lymphoma $(D L B C L)$ is rare and there are few data to guide management. We sought to further define prognosis and outcomes. Materials and Methods: We utilized the Surveillance, Epidemiology, and End Results registry to identify patients with stage I splenic DLBCL diagnosed 1973-2013. Patients were divided into two cohorts based on the year of diagnosis (1983-2005; 2006-2013) as rituximab was approved by the U.S. Food and Drug Administration in 2006 for first-line treatment of DLBCL. Results: Utilization of splenectomy decreased after the approval of rituximab ( $82 \%$ pre-versus $72 \%$ rituximab-era). Disease-specific and overall survival were greater with splenectomy [hazard ratio $(H R)=0.57, p=0.04$; and $H R=0.66, p=0.03$, respectively], but this benefit was only seen in the pre-rituximab cohort, not in the rituximab-era cohort. There was a trend toward improved overall survival with the introduction of rituximab $(H R=0.75, p=0.054)$. Conclusion: Utilization of splenectomy for stage I splenic DLBCL has decreased with the introduction of rituximab without compromising outcomes.
\end{abstract}

Primary diffuse large B-cell lymphoma (DLBCL) of the spleen is a rare finding. Originally, Dasgupta et al. defined primary splenic lymphoma (PSL) as being confined to the spleen and hilar nodes (1). Kehoe and Straus modified the definition to include disease that was thought to have started in the spleen or had the bulk of disease confined to the spleen (2). Most studies have selected patients based on the definition of PSL that falls within this spectrum of definitions. The spleen is reported to be involved in $15-40 \%$ of all non-Hodgkin's lymphoma, with up to $50-80 \%$ involvement at autopsy $(3,4)$. However, the majority are not

Correspondence to: Kenneth P. Byrd, West Cancer Center. 7945 Wolf River Blvd, Germantown, TN 38138, U.S.A. Tel: +1 9015731305, e-mail: kbyrd10@uthsc.edu

Key Words: Splenic lymphoma, large cell lymphoma, rituximab, Rituxan, B-cell lymphoma, splenectomy. considered PSLs. PSL is usually only found in 1-6\% of lymphoma cases (3-5). Classically, PSL is most commonly small B-cell lymphoma, such as marginal zone, mantle cell and follicular lymphoma $(3,5,6)$. Reports have shown that PSL can also be DLBCL subtype, but less commonly (7-8).

Studies to date suggest that primary splenic DLBCL is not a distinct pathological entity, but just a variation of DLBCL $(2,5)$. This would suggest that similar treatment guidelines for a more common stage I DLBCL entity could apply to stage I splenic DLBCL. With the U.S. Food and Drug Administration approval of rituximab in 2006, it was incorporated into the standard systemic treatment for stage I DLBCL. Interestingly, studies focused on limited-stage disease (stage I and II) were mostly done in the prerituximab era. In 1998, the SWOG 8736 study showed that three cycles of cyclophosphamide, doxorubicin, vincristine, and prednisone (CHOP) plus radiation was superior to eight cycles of CHOP in limited stage (67\% stage I) high-grade NHL (9). Since the introduction of rituximab, no randomized controlled trials have focused on the benefit of rituximab in the treatment of limited-stage disease. However, the SWOG 0014 trial showed the progression-free survival benefit of three cycles of rituximab-CHOP (R-CHOP) plus radiation in limited-stage disease compared to historical controls (10). The only randomized trial showing survival benefit of rituximab in DLBCL had very few patients with stage I disease. Interestingly, the original LNH-98.5 study showing survival benefit of R-CHOP versus CHOP in DLBCL only included a single patient with stage I disease $(11,12)$. Subsequent studies have also had an under-representation of stage I disease ranging from 7-20\% (13-15).

Overall stage I splenic DLBCL is rare and there are few data to guide management. Potential treatment modalities include combinations of splenectomy, radiation and immunochemotherapy, but there continues to be no consensus on the optimal approach. Splenectomy is the most definitive means of diagnosis, but has certain risks. The complication rate ranges from $6-22 \%$ and mortality rate up to $4 \%(6,16,17)$. Comparatively, a meta-analysis assessing 859 splenic biopsies found the complication rate to be $4 \%$ 
with no deaths (18). Using multiple publicly available and propriety databases, we sought to further define the prognosis and outcomes of stage I splenic DLBCL.

\section{Materials and Methods}

We utilized the Surveillance, Epidemiology, and End Results(SEER)18 registry to identify patients with stage I splenic DLBCL diagnosed during the years 1973-2013 using SEER*Stat 8.3.2. Appropriate cases were identified using a combination of International Classification of Diseases for Oncology, 3rd edition code DLBCL (9680/3) and location code for spleen (C42.2) (19). These patients were divided into two cohorts based on the year of diagnosis (1983-2005; 2006-2013) as rituximab was approved by the FDA in 2006 for use in the first-line treatment of DLBCL. Patient characteristics and survival outcomes were analyzed by GraphPad Prism 6 (GraphPad Software, Inc., La Jolla, CA, USA) and Microsoft Excel (Microsoft Corporation, Redmond, WA, USA). Disease-specific (DSS) and overall (OS) survival comparisons were made using the Gehan-Breslow-Wilcoxon test. All $p$-values were two-sided and results of 0.05 or less were considered significant.

We queried the Mitelman Database of Chromosome Aberrations and Gene Fusions in Cancer to identify patients with stage I splenic lymphoma during the years 1973-2013 (20). We also searched the Caris Life Sciences database for patients profiled by Caris Molecular Intelligence using the key words "splenic lymphoma" in the clinical history and diagnosis fields for cases of stage I splenic DLBCL from 2007-2015 (21). All database searches were conducted with Institutional Review Board approval, \#16-04517-XP.

\section{Results}

A total of 107,550 patients with known stage and histologically confirmed DLBCL were identified within the SEER database. Out of the 30,455 patients who had stage I disease, only 470 had stage I splenic DLBCL (1.5\%). The mean age was 66 years (range $=17-93$ years) and the majority were Caucasian $(89 \%)$. There was equal distribution of patients in the pre-rituximab era and post-rituximab era. Overall, 42\% (470/1116) of splenic DLBCL were diagnosed as stage I compared to $28 \%(29,985 / 106,434)$ of all other types of DLBCL $(p<0.01)$. Patients with stage I splenic DLBCL treated in the rituximab era had better OS than patients with stage I DLBCLs of other types treated during the same period [Figure 1; hazard ratio $(\mathrm{HR})=0.62,95 \%$ confidence interval $(\mathrm{CI})=0.53-0.86 ; p<0.01]$.

The rate of splenectomy was lower after the approval of rituximab ( $82 \%$ vs. $72 \%, p=0.03)$. Splenectomy was associated with an improvement in DSS (HR=0.57, 95\% $\mathrm{CI}=0.28-0.96 ; p=0.04)$. When analyzed by era, however, improved DSS with splenectomy was only seen in the prerituximab cohort $(\mathrm{HR}=0.51,95 \% \mathrm{CI}=0.17-1.08 ; p=0.04)$, but not in the rituximab-era cohort (Figure 2; HR=0.62, 95\% $\mathrm{CI}=0.25-1.38 ; p=0.53)$. OS advantage with splenectomy was also seen only in the pre-rituximab era $(\mathrm{HR}=0.66,95 \%$ $\mathrm{CI}=0.32-1.14 ; p=0.03)$ and not in the rituximab era $(\mathrm{HR}=0.74$,
95\% CI=0.37-1.43, $p=0.45$ ). Combining patients with and without splenectomy, there was a trend toward improved OS with the introduction of rituximab (Figure 3; HR $=0.75,95 \%$ $\mathrm{CI}=0.48-1.14 ; p=0.054)$. There was no significant difference in the utilization of radiation between these cohorts $(6 \%$ prerituximab versus $3 \%$ rituximab era, $p=0.13$ ).

Our search of the Mitelman database found 1,413 patients with DLBCL, but none of them had stage I splenic DLBCL. We also identified 20 patients with non-Hodgkin lymphoma profiled by Caris Life Sciences, of whom only one had primary splenic DLBCL.

\section{Discussion}

Prior studies have shown that primary splenic lymphoma represents $1-6 \%$ of all non-Hodgkin's lymphomas $(3,4)$. Our study is mostly consistent with these findings as our SEER review found that $1 \%$ of stage I DLBCL was PSL, but primary splenic DLBCL was even less common in other databases. PSL is more likely to present as stage I disease compared to other types of DLBCLs and stage I splenic DLBCL appears to have a favorable prognosis relative to other stage I DLBCLs. It is more common in middle-aged patients, with a mean age of 66 years at diagnosis.

Current treatment of stage I primary splenic DLBCL often includes surgery and immunochemotherapy based on limited data (4). More robust data are available for the treatment of low-grade B-cell PSL, especially primary splenic marginal zone lymphoma (MZL). Early studies showed benefit of splenectomy as first-line therapy for splenic MZL (22). However, since the advent of rituximab, some have suggested that splenectomy can be abandoned as first-line treatment for splenic MZL as rituximab alone has $88-100 \%$ response rate $(23,24)$. Moreover, Musteata et al. suggested that early splenectomy along with combination chemotherapy was the optimal treatment for low-grade PSL, leading to higher response rates, progression-free survival, and OS compared to chemotherapy alone (25). For those unable to undergo splenectomy, local radiotherapy has historically been considered for low-grade PSL (25). Our review of splenic DLBCL found that radiation is rarely used and does not appear to influence outcomes.

One difficulty in assessing the best treatment for stage I splenic DLBCL is that most studies are retrospective and group all histological subtypes of PSL together. Small studies of PSL with DLBCL subtype show good response to splenectomy while most also received adjuvant chemotherapy/radiation (8). In a retrospective study of 87 patients with splenic DLBCL, splenectomy at diagnosis improved survival. The vast majority of these patients received adjuvant $\mathrm{CHOP}$-based chemotherapy (92\%), while $83 \%$ had treatment that included rituximab (26). In a small study of 59 patients with PSL (16 had intermediate- to high- 


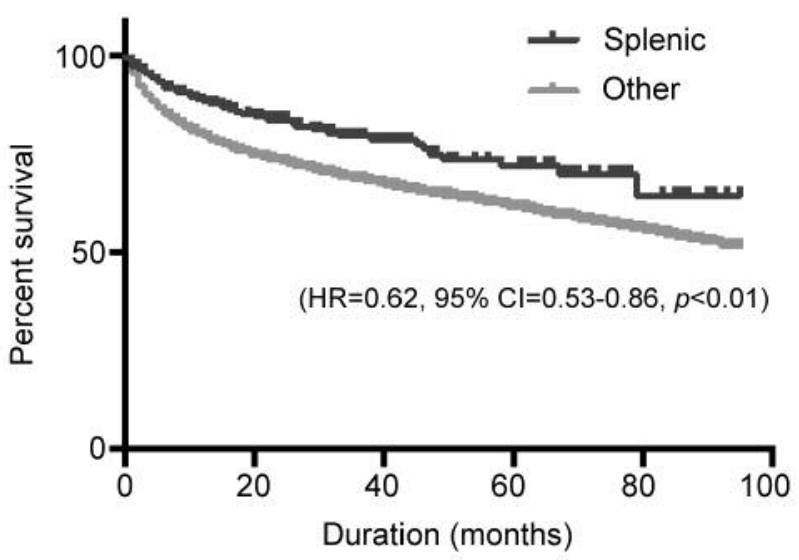

Figure 1. Overall survival of patients with stage I splenic diffuse large $B$-cell lymphoma versus those with all other types of stage I diffuse large B-cell lymphomas assessed from time of diagnosis. Data source: Surveillance, Epidemiology, and End Results registry. CI: Confidence interval: HR: hazard ratio.

grade lymphoma), the median survival was 108 months in those who underwent splenectomy and 24 months in those not treated surgically. However, rituximab was not available at the time of that study (4). With the advent of rituximab in 2006, the standard systemic treatment for DLBCL now includes this agent. It is reasonable to consider it also as standard treatment for splenic DLBCL. It is unclear if patients with surgically resected primary splenic DLBCL should undergo adjuvant treatment. Some studies have recommended splenectomy alone and very few have demonstrated the benefit of adjuvant chemotherapy following splenectomy in these patients (2-5, 24-26). However, since there is a paucity of data, we could rationally adopt the same strategy that is used for DLBCL patients with surgically resected localized extra nodal disease. This would include the use of CHOP plus rituximab for four cycles (5).

Our data show that there is a trend towards improved OS after the introduction of rituximab in patients with stage I splenic DLBCL. Prior studies of all stages of PSL in the prerituximab era suggested a 5-year survival rate of $31-40 \%$ (27). We found the median OS of patients with stage I splenic DLBCL in the post-rituximab era to be 11 years. We also showed that splenectomy improved DSS and OS in stage I splenic DLBCL, but the benefit was only seen prior to the introduction of rituximab. Therefore, it is still unclear if splenectomy is a necessary part of treatment in the era of rituximab. Splenectomy is irreversible and consequently leads to the loss of its multiple hematological and immunological functions. Our data show that splenectomy lost its impact on OS after introduction of rituximab. They also demonstrate that the usage of rituximab has reduced the rate of

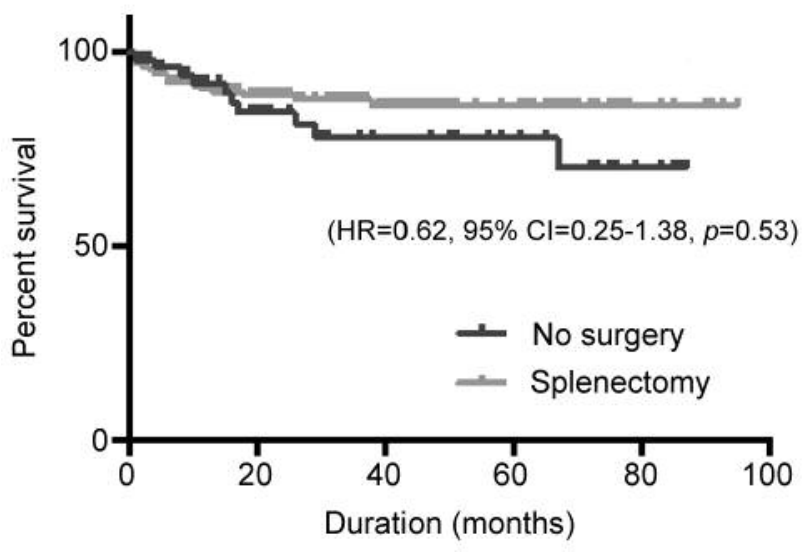

Figure 2. Disease-specific survival of patients with stage I splenic diffuse large B-cell lymphoma treated with or without splenectomy during the rituximab era assessed from time of diagnosis. Data source: Surveillance, Epidemiology, and End Results registry.

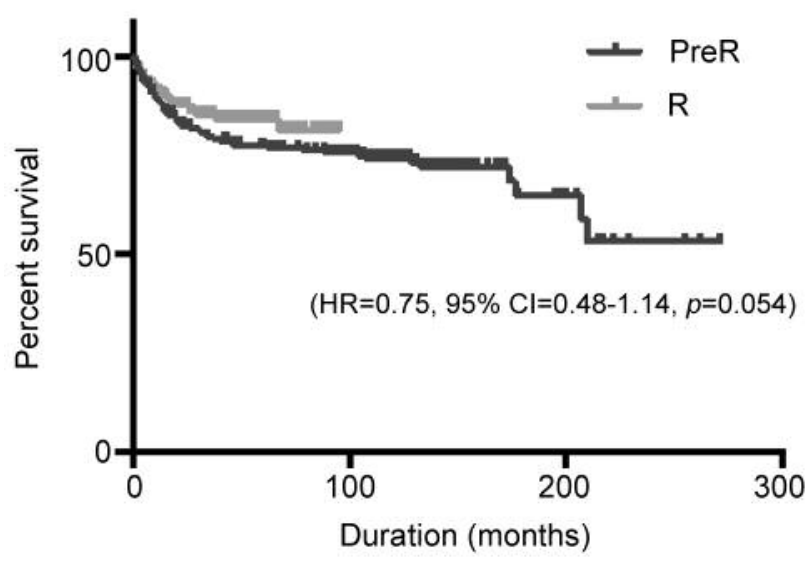

Figure 3. Overall survival of patients with stage I splenic diffuse large $B$-cell lymphoma in the pre-rituximab (PreR) era and rituximab era $(R)$ assessed from time of diagnosis. Data source: Surveillance, Epidemiology, and End Results registry.

splenectomy without compromising OS. It is quite possible that chemotherapy alone can cure stage I splenic DLBCL like other early stage DLBCLs, but this has not yet been proven.

Historically splenectomy was considered the most effective therapy for PSL because it is both diagnostic and therapeutic $(28,29)$. Splenic biopsy or splenectomy is often required for definitive diagnosis of PSL (30). Moreover, of all patients assessed for splenomegaly, 16-57\% have malignancy by tissue diagnosis, most commonly lymphoma $(7,16)$. However, the diagnosis of PSL may sometimes be 
achieved by examination, imaging, peripheral smear and bone marrow biopsy without the need for splenectomy. Ultrasound usually shows hypoechoic lesions, while computed tomography shows hypodense lesions $(31,32)$. More specifically for DLBCL of the spleen, imaging will show large nodular or small nodular pattern $(33,34)$. Moreover, 59-70\% of patients with stage I splenic DLBCL have B-symptoms $(26,35)$. For splenic MZL, the bone marrow is invariably involved and the peripheral blood smear shows malignant cells in most PSL (22). However, the bone marrow is only involved in $<10 \%$ of splenic DLBCL cases and the peripheral smear is often nondiagnostic (26). Iannitto and Tripodo reported that only 5\% of all PSLs require splenectomy in addition to bone marrow biopsy and peripheral smear review for diagnosis, but it is unclear if this specifically applies to the DLBCL subtype (5). Therefore, splenectomy may still be required for the diagnosis of splenic DLBCL, but it is not clear that it is a therapeutic necessity.

Our SEER analysis found that the utilization of splenectomy for stage I splenic DLBCL has decreased with the introduction of rituximab without compromise of outcomes. Alternative databases added little to the understanding of the biology of stage I splenic DLBCL. Complications of splenectomy include infection and hemorrhage, which can be fatal at times. There has been an increased tendency in recent years towards splenic preservation to prevent these complications. We need more studies to demonstrate the clinical benefit of rituximab-based chemotherapy without splenectomy in stage I splenic DLBCL and the long-term survival outcomes.

\section{References}

1 Dasgupta T, Coombes B and Brasfield RD: Primary malignant neoplasm of the spleen. Surg Gynecol Obstet 120: 947-960, 1965.

2 Kehoe $\mathbf{J}$ and Straus DJ: Primary lymphoma of the spleen. Clinical features and outcome after splenectomy. Cancer 62(7): 1433-1438, 1988.

3 Brox A, Bishinsky JI and Berry G: Primary non-Hodgkin lymphoma of the spleen. Am J Hematol 38(2): 95-100, 1991.

4 Morel P, Dupriez B, Gosselin B, Fenaux P, Estienne MH, Facon T, Jouet JP and Bauter F: Role of early splenectomy in malignant lymphomas with prominent splenic involvement (primary lymphomas of the spleen). A study of 59 cases. Cancer 71(1): 207-215, 1993.

5 Iannitto $\mathrm{E}$ and Tripodo C: How I diagnose and treat splenic lymphomas. Blood 117(9): 2585-2595, 2011.

6 Carr JA, Shurafa M and Velanovich V: Surgical indications in idiopathic splenomegaly. Arch Surg 137(1): 64-68, 2002.

7 Kraus MD, Fleming MD and Vonderheide RH: The spleen as a diagnostic specimen: a review of 10 years' experience at two tertiary care institutions. Cancer 91(11): 2001-2009, 2001.

8 Grosskreutz C, Troy $\mathrm{K}$ and Cuttner J: Primary splenic lymphoma: report of 10 cases using REAL classification. Cancer Invest 20(5-6): 749-753, 2002.
9 Miller TP, Dahlberg S, Cassady JR, Adelstein DJ, Spier CM, Grogan TM, LeBlanc M, Carlin S, Chase E and Fisher RI: Chemotherapy alone compared with chemotherapy plus radiotherapy for localized intermediate- and high-grade nonHodgkin's lymphoma. New Engl J Med 339(1): 21-26, 1998.

10 Persky DO, Unger JM, Spier CM, Stea B, LeBlanc M, McCarty MJ, Rimsza LM, Fisher RI and Miller TP: Phase II study of rituximab plus three cycles of $\mathrm{CHOP}$ and involved-field radiotherapy for patients with limited-stage aggressive B-cell lymphoma: Southwest Oncology Group study 0014. J Clin Oncol 26(14): 2258-2263, 2008.

11 Coiffier B, Lepage E, Briere J, Herbrecht R, Tilly H, Bouabdallah R, Morel P, Van Den Neste E, Salles G, Gaulard P, Reyes F, Lederlin P and Gisselbrecht C: CHOP chemotherapy plus rituximab compared with $\mathrm{CHOP}$ alone in elderly patients with diffuse large-B-cell lymphoma. New Engl J Med 346(4): 235-242, 2002.

12 Coiffier B, Thieblemont C, Van Den Neste E, Plantier I, Castaigne S, Lefort S, Marit G, Marco M, Sebban C, Belhadj K, Bordessoule D, Ferme C and Tilly H: Long-term outcome of patients in the LNH-98.5 trial, the first randomized study comparing rituximab-CHOP to standard CHOP chemotherapy in DLBCL patients: a study by the Groupe d'Etudes des Lymphomes de l'Adulte. Blood 116(12): 2040-2045, 2010.

13 Habermann TM, Weller EA, Morrison VA, Gascoyne RD, Cassileth PA, Cohn JB, Dakhil SR, Woda B, Fisher RI, Peterson $\mathrm{BA}$ and Horning SJ: Rituximab-CHOP versus $\mathrm{CHOP}$ alone or with maintenance rituximab in older patients with diffuse large B-cell lymphoma. J Clin Oncol 24(19): 3121-3127, 2006.

14 Pfreundschuh M, Schubert J, Ziepert M, Schmits R, Mohren M, Lengfelder E, Reiser M, Nickenig C, Clemens M, Peter N, Bokemeyer C, Eimermacher H, Ho A, Hoffmann M, Mertelsmann R, Trumper L, Balleisen L, Liersch R, Metzner B, Hartmann F, Glass B, Poeschel V, Schmitz N, Ruebe C, Feller AC and Loeffler M: Six versus eight cycles of bi-weekly CHOP14 with or without rituximab in elderly patients with aggressive CD20+ B-cell lymphomas: a randomised controlled trial (RICOVER-60). Lancet Oncol 9(2): 105-116, 2008.

15 Pfreundschuh M, Trumper L, Osterborg A, Pettengell R, Trneny M, Imrie K, Ma D, Gill D, Walewski J, Zinzani PL, Stahel R, Kvaloy S, Shpilberg O, Jaeger U, Hansen M, Lehtinen T, LopezGuillermo A, Corrado C, Scheliga A, Milpied N, Mendila M, Rashford M, Kuhnt E and Loeffler M: CHOP-like chemotherapy plus rituximab versus CHOP-like chemotherapy alone in young patients with good-prognosis diffuse large-B-cell lymphoma: a randomised controlled trial by the MabThera International Trial (MInT) Group. Lancet Oncol 7(5): 379-391, 2006.

16 Bagrodia N, Button AM and Spanheimer PM: Morbidity and mortality following elective splenectomy for benign and malignant hematologic conditions: analysis of the American College of Surgeons National Surgical Quality Improvement Program data. JAMA Surg 149(10): 1022-1029, 2014.

17 Xiros N, Economopoulos T, Christodoulidis C, Dervenoulas J, Papageorgiou E, Mellou S, Tsirigotis P, Bolas G and Raptis S: Splenectomy in patients with malignant non-Hodgkin's lymphoma. Eur J Haematol 64(3): 145-150, 2000.

18 McInnes MD, Kielar AZ and Macdonald DB: Percutaneous image-guided biopsy of the spleen: systematic review and metaanalysis of the complication rate and diagnostic accuracy. Radiology 260(3): 699-708, 2011. 
19 International Classification of Diseases for Oncology, Third Edition, First Revision. Geneva: World Health Organization, 2013.

20 Mitelman F, Johansson B and Mertens F: Mitelman Database of Chromosome Aberrations and Gene Fusions in Cancer, 2016. http://cgap.nci.nih.gov/Chromosomes/Mitelman/

21 Caris Life Sciences. Phoenix, AZ. 2016. https:// www.carislifesciences.com/

22 Franco V, Florena AM and Iannitto E: Splenic marginal zone lymphoma. Blood 101(7): 2464-2472, 2003.

23 Kalpadakis C, Pangalis GA, Vassilakopoulos TP, Sachanas S and Angelopoulou MK: Treatment of splenic marginal zone lymphoma: Should splenectomy be abandoned? Leuk Lymphoma 55(7): 1463-1470, 2014.

24 Bennett $M$ and Schechter GP: Treatment of splenic marginal zone lymphoma: splenectomy versus rituximab. Semin Hematol 47(2): 143-147, 2010.

25 Musteata VG, Corcimaru IT, Iacovleva IA, Musteata LZ, Suharschii IS and Antoci LT: Treatment options for primary splenic low-grade non-Hodgkin's lymphomas. Clin Lab Haematol 26(6): 397-401, 2004.

26 Bairey O, Shvidel L, Perry C, Dann EJ, Ruchlemer R, Tadmor $\mathrm{T}$ and Goldschmidt $\mathrm{N}$ : Characteristics of primary splenic diffuse large B-cell lymphoma and role of splenectomy in improving survival. Cancer 121(17): 2909-2916, 2015.

27 Ahmann, DL, Kiely JM, Harrison EG and Payne WS: Malignant lymphoma of the spleen: a review of 49 cases in which the diagnosis was made at splenectomy. Cancer 19(4): 461-469, 1966.

28 Izzo L, Binda B, Boschetto A, Carmanico L, Galati G, Fiori E, Lo Mele L and Stasolla A: Primary Splenic Lymphoma: diagnostic and therapeutic value of splenectomy. Haematologica 87(6): ECR20, 2002.
29 Healy NA, Conneely JB, Mahon S, O'Riardon C and McAnena OJ: Primary splenic lymphoma presenting with ascites. Rare Tumors 3(2): e25, 2011.

30 Dachman AH, Buck JL, Krishnan J, Aguilera NS and Buetow PC: Primary non-Hodgkin's splenic lymphoma. Clin Radiol 53(2): 137-142, 1998.

31 Kim JK, Hahn JS, Kim GE and Yang WI: Three cases of diffuse large B-cell lymphoma presenting as primary splenic lymphoma. Yonsei Med J 46(5): 703-709, 2005.

32 Solbiati L, Bossi MC, Bellotti E, Ravetto C and Montali G: Focal lesions in the spleen: sonographic patterns and guided biopsy. Am J Roentgenol 140(1): 59-65, 1983.

33 Mollejo M, Algara P, Mateo MS, Menarquez J, Pascual E, Fresno MF, Camacho FI and Piris MA: Large B-cell lymphoma presenting in the spleen: identification of different clinicopathologic conditions. Am J Surg Pathol 27(7): 895-902, 2003.

34 Gorg C, Weide R and Schwerk WB: Malignant splenic lymphoma: sonographic patterns, diagnosis and follow-up. Clin Radiol 52(7): 535-540, 1997.

35 Harris NL, Aisenberg AC, Meyer JE, Ellman L and Elman A: Diffuse large cell (histiocytic) lymphoma of the spleen. Clinical and pathologic characteristics of ten cases. Cancer 54(11): 24602467, 1984.
Received August 23, 2017

Revised October 16, 2017

Accepted October 18, 2017 